\title{
A NOVEL APPROACH OF LIFT CONTROL IN AUTOMATIC CAR PARKING USING PLC
}

\author{
Sharadchandra A. Amale ${ }^{1}$, Sanjay A. Pardeshi ${ }^{2}$ \\ ${ }^{1}$ PG Student [Digital Systems], Dept. of ECE, Rajarambapu Institute of Technology, Maharashtra, India \\ ${ }^{2}$ Professor, Dept. of ECE, Rajarambapu Institute of Technology, Maharashtra, India
}

\begin{abstract}
In the today situation, where parking of four wheeler vehicle is very severe problem in urban region. It is crucial time to avoid the wastage of space in urban areas, as the no of vehicles are increasing day by day. An automatic parking (multilevel) strategy should be developed where parking problems arise intensively, which involves space reduction. In this paper a novel approach for lift control is proposed in fully automatic Level Car Parking System which used to take cars in/out of system \& park the cars. Entire system is controlled using a Programmable Logic Controller (PLC). As speed control is required for multiple speed setting \& proper stopping accuracy, the lift will be driven by the VFD (Variable Frequency Drive) for speed control. The pallet position on lift, accurate positioning between lift-level \& safety interlocks are sensed from dedicated sensor. EPLAN software for used for electrical panel design purpose whileTWINCAT PLC control is used for auto/manual modes programming \& simulated results.
\end{abstract}

Keywords: Lift control, Automatic Parking, PLC programming, IEC standard 61131-3. $* * *$

\section{INTRODUCTION}

With increase in trade and commerce in the Indian metro cities, the number of vehicles has increased abruptly. These cities bring in considerable amount of cars. Also despite of fact that there are multiple parking spaces available for metro cities, the parking capacity of these parking spaces is not sufficient to satisfy to the current demand \& also the parking space location is questionable. The side of the street are occupied with parked vehicles leading to a major bottleneck in the smooth flow of traffic due to the absence of adequate parking facilities. For solving the problem of finding parking space for the increasing number of vehicles, Multi-level parking lots at strategic places and a rational parking fee are inevitable. An automatic car parking system (ACPS) is a kind of mechanical system developed to reduce the area and volume needed for parking the cars.With rising safety \& comfort standards and attention towards safety measures and with the development in modern technologic, elevator systems in car parking are getting better, fast and more reliable. PLC can make a conventional elevator system into an automatic, energy saving, safe and reliable elevator system by using various math functions, timers, creating interlocks etc. into its program [1].As Lifts were used as vertical transport tool, which belong to potential energy load and require frequent start and stop. Traditional relay control modes were replaced by PLC control method, which could gradually transited from DC speed adjusting system to AC variable frequency speed adjusting system [2]. With the higher and quicker development of elevators, the safety has became more and more important and safety device becomes particular vital. Besides the hardware, the program's security is also significant. Except putting the necessary limit switches and self locking program into some main drive circuit, the program should also be equipped with safety procedures [3].
In this paper, automatic control of lift in automatic car parking system is proposed. The total system is having two lifts, three level transfer mechanisms. A single PLC (BECKHOFF PLC) is used to control the entire parking system. For accurate speed control lift is operated with VFD. Speed control is required for acceleration/ deceleration \& proper stopping accuracy. The flow sequences are designed according to system sequence for lift for manual mode $\&$ auto mode operations. The lift will be given command to go to specific level depending upon the storage pallet or parked car location in system. The organization of rest of paper is as fallows sensor overview of lift is explained in section 2. Electrical wiring diagram of VFD in section 3. Algorithm, Flowcharts in auto \& manual mode \& elevator module are explained in section 4. Performance analysis \& simulation results are explained in section 5 Concluding remarks are given in section 6.

\section{OVERVIEW DIAGRAM OF LIFT}

Level car parking system intends to develop an automatic car parking system with easier storage \& retrieval of cars. The lift positions feedback are obtained from dedicated sensors. The sensors overview along with lift movement direction is represented in Fig. 1.

1. Fork sensor. This sensor is fixed and the dogs are mounted at each slat location. When input from this sensor is received the lift speed will be reduced.

2. Slat Position confirmation sensor: This is a retroreflective sensor. This sensor are be used to confirm that the lift has reached the correct position and the transfer of pallet to be done is safe.

3. Pallet position on Lift: These sensors are mounted at each level for position confirmation. When input from this sensor is received then the speed of lift reduced. During the Auto mode this sensor is used to 
insure the pallet position confirmation on the pallet, thus ensuring that the pallet has reached on lift.

4. Safety sensors: If the lift pallet not engaged properly during up/down movements, then Height/AntiLift sensors cut and stop the operation of Lift. The over travel sensors used to alarm the system that lift is going above the safe position limits.

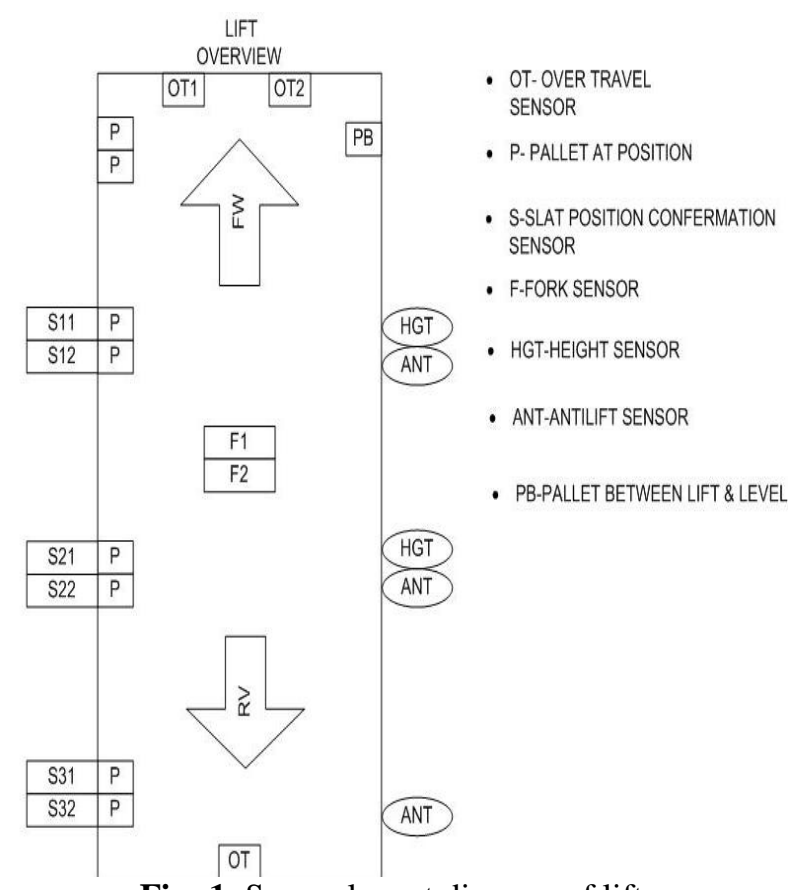

\section{ELECTRICAL WIRING DIAGRAM OF VFD}

The job of multispeed drive is completed with VFD and logic/Boolean control section is completed with PLC controller. The logic relatives of various signals are responsible for PLC to send on/off control signals to inverter. At the same time, the working status from inverter is transported to PLC. The VFD connection to load as lift motor \& braking circuit is shown in shown in Fig. 2. The VFD is given supply of $415 \mathrm{VAC} \&$ protected it by MCB \& choke rating greater than the motor rating. The control signals received from the PLC to VFD are Commands as Forward, Backward, slow speed, high speed, \& reset. Also PLC receives feedback from VFD in terms of Run \& Fault status signals. The connections are made to drive the motor in forward direction, to drive the motor in reverse direction, to control the speed of the motor in both directions. As shown in circuit diagram for forward (clockwise) direction STF terminal is used and to drive the motor in reverse (anticlockwise) direction STR terminal is used. SD is common/reference terminal for both STF and STR terminals [4].

Fig -1: Sensor layout diagram of lift

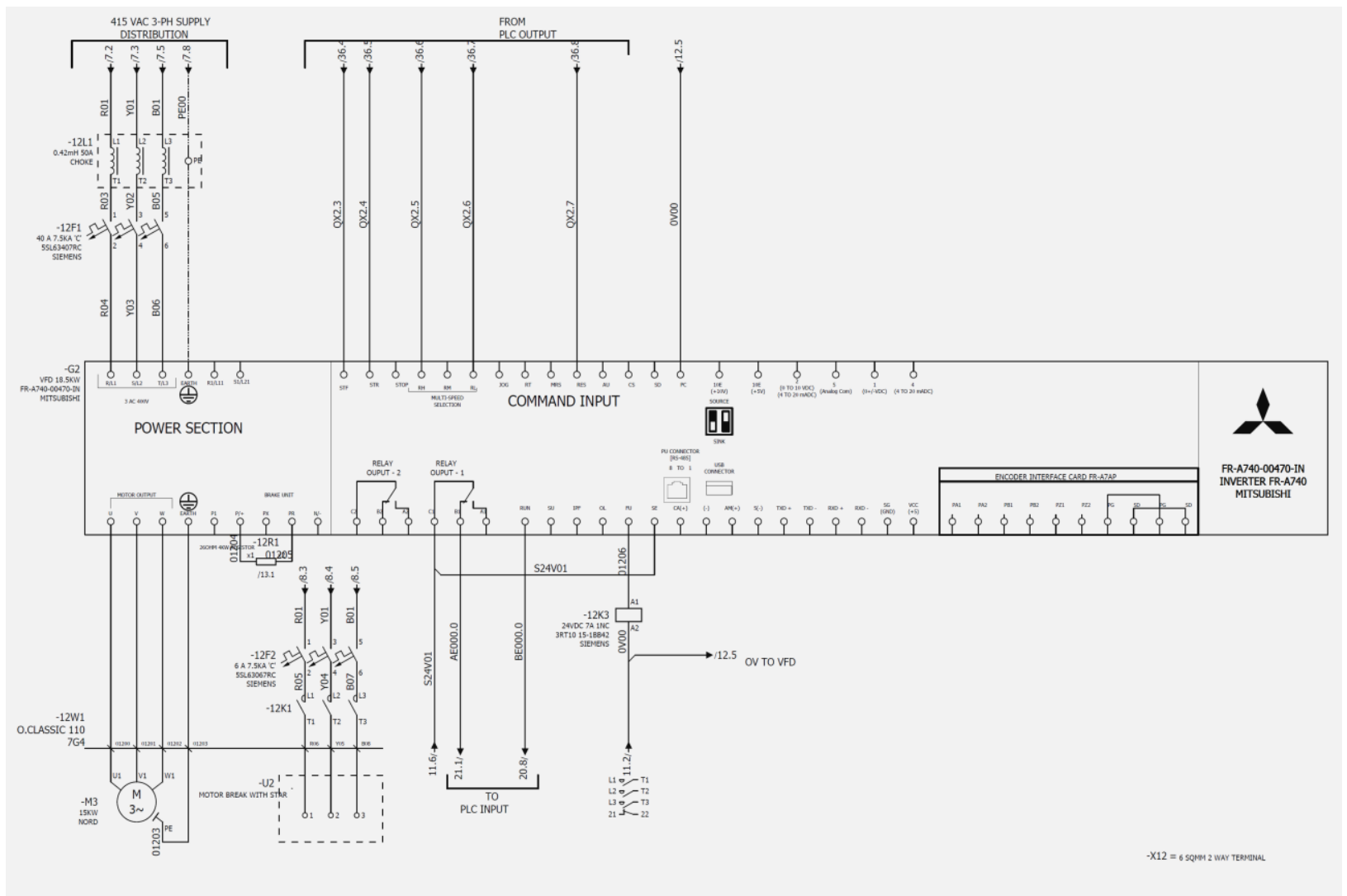

Fig -2: Electrical diagram of VFD connection 


\section{OPERATIONAL SEQUENCE}

Sequence of operation

There are two types of sequences manual mode sequence and auto mode sequence.

1) Manual Mode: a) The lift manual mode operation is inching. b) The lift inched with spring action button in up or down direction for maintenance work. c) Facility to change the speed will not be given. d) The speed in the manual/maintenance mode is slow speed. e) All manual mode actions are done from the HMI or from teach pendant.

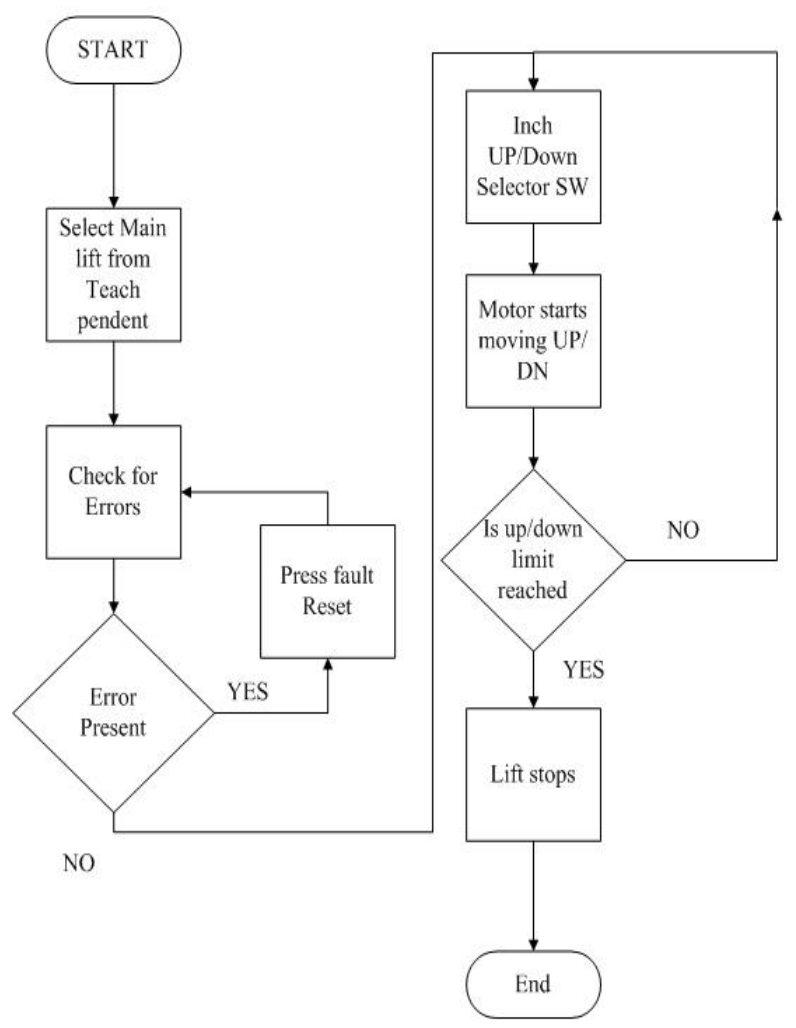

Fig -3: Manual Mode operation sequence

2) Auto Mode: a) lift is always waiting for command in auto mode as shown in Fig. 4 b) The command given to the lift is in terms of direction and number of levels to move. c) depending upon the command direction lift starts to move respective direction d) Once slow sensor(fork sensor) is sensed the speed of the VFD is made slow. e) As soon as the stop sensor(fork sensor) is sensed the lift stops. f) The level position sensors are checked to ensure that the lift is stopped correctly. If there is a level difference, then the level confirmation sensor will not be sensed and error will be given [5].

Example:

If the destination level where the pallet needs to be transferred is less than the source level where the pallet is currently present, then the direction of the lift will be up and vice versa. So following will be the decision taken by the lift module.
Current pallet level: 2 \& Level to go: 1

Then Number of levels to move $=$ destination level no source level no $=1-2=-1$. I.e. Counter value $=1$. Since the number of levels to move $<0$ so the direction is be up and the level counter is initialized to 1 .

When lift is given down command, then the counter value is be positive as shown below in example.

Current pallet level: 1 \& Level to go: 3

Then Number of levels to move $=$ destination level no source level no $=3-1=2$. I.e. Counter value $=2$. Here no of levels is positive, it means that lift has given down command \& two levels to move.

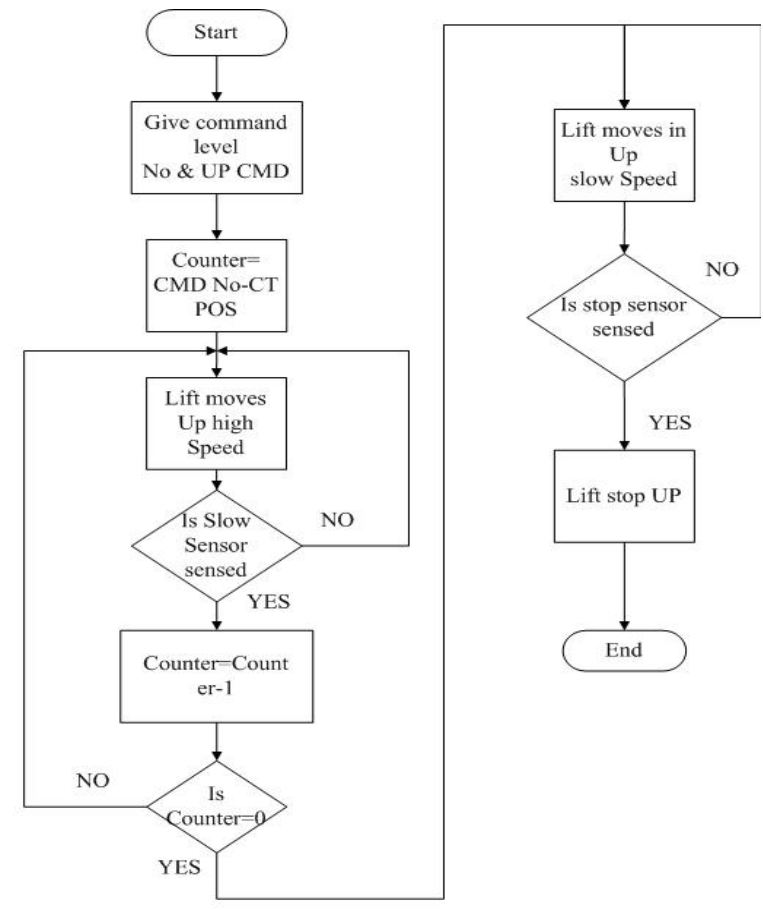

Fig -4: Auto mode operation sequence

\section{RESULTS}

TWINCAT PLC Control is a complete development environment for your PLC. TWINCAT PLC Control puts a simple approach to the powerful IEC language at the disposal of the PLC programmer. Use of the editors and debugging functions is based upon the proven development program environments of advanced programming languages. TWINCAT PLC Control is a complete development tool used to program your PLC which will save a measurable amount of time setting up applications.

\subsection{Simulation Results}

When the lift is kept in auto mode, the simulation is represented as in Fig. 5 at right side. The auto mode operation for lift is shown for upward direction. The current position of the lift is at Level $1 \&$ command level now is level 0 . So counter value is moved with as Counter value= Command Level- Current Position level. I.e. Counter value 
moved is 1 . As the difference is a negative value, then lift will move in upward direction else in a downward direction for the opposite case. Lift is kept in auto mode cycle start is pressed then lift starts moving in upward direction indicated with upward arrows as 'FW'. Tower lamp continuously green indicating lift is operating in auto mode.

As shown in Fig. 6 at left side manual mode operation for lift in downward direction. The current position of the lift is sensed by pallet position sensors denoted as ' $\mathrm{P}$ ' \& two fork sensors denoted as 'F1' \& 'F2'. Fork sensors are used as slow speed \& stop speed indication. Lift is kept in manual mode $\&$ the main lift down button is pressed, the lift reverse arrow denoted as ' $R V$ ' is High, indicating lift is moving down until down limit is reached. Here down level limit is level no 3 \& current lift position is at level no 1 as position sensors are set for this level. As soon as main lift down button is released, lift stop instantly at that time. Main lift always moves in slow speed when it is operating in manual mode. Tower lamp shows amber \& blinking green lamp as an indication of lift operating in manual mode.
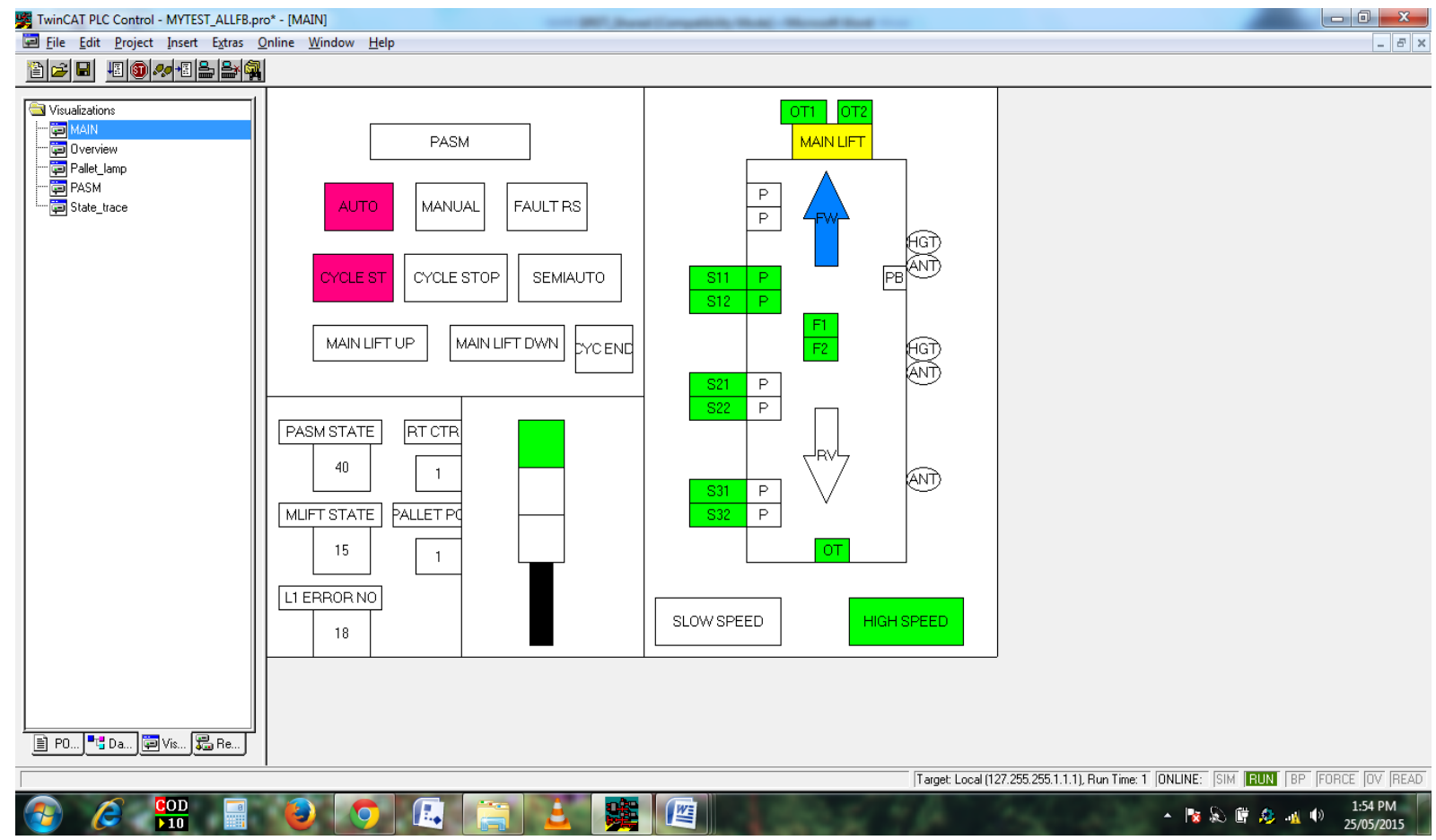

Fig -5: Auto mode simulation

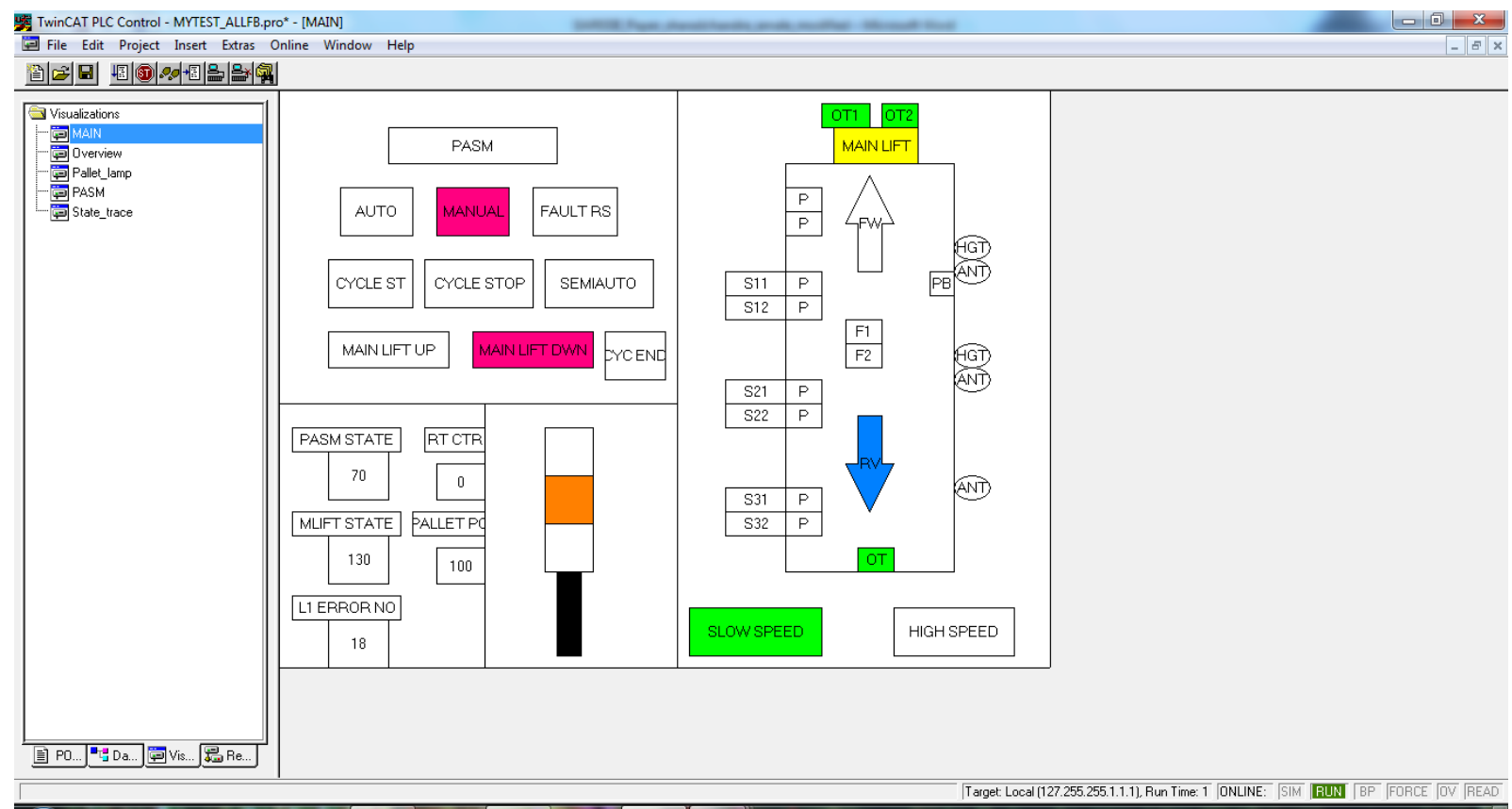

(A) Q C C.0D

Fig -6: Manual mode simulation 


\subsection{Input/ Output Testing}

Table -1: I/O \& communication testing

\begin{tabular}{|l|l|l|l|}
\hline $\begin{array}{l}\text { Sr. } \\
\text { No. }\end{array}$ & $\begin{array}{l}\text { Points to be } \\
\text { Checked }\end{array}$ & $\begin{array}{l}\text { Target } \\
\text { ed }\end{array}$ \\
\hline 1 & Input Testing & $\begin{array}{l}\text { As per } \\
\text { input list }\end{array}$ & Tested ok \\
\hline 2 & $\begin{array}{l}\text { Output } \\
\text { Testing }\end{array}$ & $\begin{array}{l}\text { As per } \\
\text { Output list }\end{array}$ & Tested ok \\
\hline 3 & $\begin{array}{l}\text { Communicati } \\
\text { on testing } \\
\text { between HMI } \\
\text { \& PLC }\end{array}$ & $\begin{array}{l}\text { As per RS } \\
422 / 485 \\
\text { Standard }\end{array}$ & $\begin{array}{l}\text { Tested All HMI } \\
\text { tags }\end{array}$ \\
\hline
\end{tabular}

Input testing are completed with reference to input list in CMS (Control mechanical Sign-off) sheet \& checked working conditions of inputs to PLC such as sensors, buttons \& switches. For BECKHOFF PLC inputs indexed with notation as "IX0.0" \& outputs are represented as notation "QX0.0". Output testing are performed with output list form CMS sheet \& checked the working conditions of actuators like lamp, motor, buzzer etc. are shown in table 1 .

\section{CONCLUSION}

Automatic control of lift in Level Type Car Parking System is designed which used to take cars in \& out of system to park. The system has several advantages to conventional car parking system lift like reduction in construction costs, cycle time, space requirements, highly secure \& pollution control. In addition to this, lift stopping accuracy is quite accurate due to presence of pallet position sensors placed at all levels. In this paper for human \& machine safety, interlocks are used which take care of healthy condition all time. Whenever an alarm occurs whole lift goes into emergency case where the operator needs to acknowledge alarm to avoid major accidents at parking. The alarm system has been designed which ensures more safety of operator.

\section{ACKNOWLEDGEMENTS}

I would like to thanks my project supervisor Dr. S. A. Pardeshi for providing the valuable guidance \& Department of Electronics \& Telecommunication, Rajarambapu Institute of Technology, Islampur \& PARI LTD.

\section{REFERENCES}

[1] G. Singh, A. Agarwal, R.K. Jarial, V.Agarwal, M. Mondal, "PLC controlled elevator system", in Proc. IEEE Engineering and Systems (SCES) 2013, pp. 1 5, Feb 2013.

[2] J. Jing, Z. Xuesong, "Variable frequency speedregulation system of elevator using PLC technology", in Proc. IEEE Advanced Computer Control (ICACC) 2011, pp. 328 - 332, Jan 2011.

[3] L. Jun, L. Min, "Development of Elevator Intelligent Safety Control System Based on PLC", in Proc. IEEE Computational and Information Sciences (ICCIS)2013, pp.1963 - 1966, Jun 2013.
[4] X.Yan,Q. Zhu, H. Xu, "Design and Practice of an Elevator Control System Based on PLC", in Proc. IEEE Workshop on Power Electronics and Intelligent Transportation System 2008, pp. 94 - 99, Apr 2008.

[5] Y. Huang, J. Chen, S. Lee, Y.Weng, "Design of Elevator Control Systems Using Statecharts", in Proc. IEEE International Conference on Networking, Sensing and Control (ICNSC) 2013, pp. 322 - 327, Aug 2013.

\section{BIOGRAPHY}

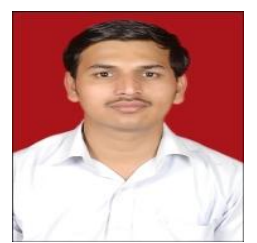

Sharadchandra A. Amale, born in Solapur District, Maharashtra, India in 1987. He received B.E. degree in Electronics and Telecommunication Engineering at Walchand Institute of Technology from Solapur University in 2009 and now pursuing M-Tech. in Electronics-Digital Systems at Rajarambapu Institute of Technology, Islampur (Sangli). His research of focus is on Automation and Robotics. 